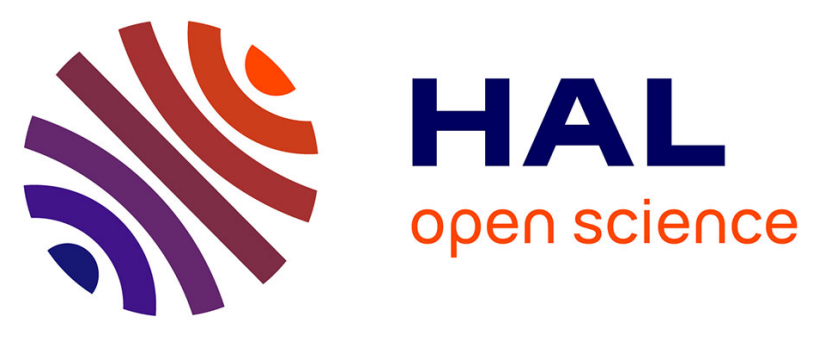

\title{
Knowledge of free voluntary HIV testing centres and willingness to do a test among migrants in Cayenne, French Guiana
}

\author{
Matthieu Hanf, Véronique Bousser, Marie Claire Parriault, Astrid Van-Melle, \\ Marie-Louise Nouvellet, Leila Adriouch, Claire Goddard-Sebillotte, Pierre \\ Couppié, Mathieu Nacher
}

\section{To cite this version:}

Matthieu Hanf, Véronique Bousser, Marie Claire Parriault, Astrid Van-Melle, Marie-Louise Nouvellet, et al.. Knowledge of free voluntary HIV testing centres and willingness to do a test among migrants in Cayenne, French Guiana. AIDS Care, 2011, 23 (04), pp.476-485. 10.1080/09540121.2010.525604 . hal-00665442

\section{HAL Id: hal-00665442 \\ https://hal.science/hal-00665442}

Submitted on 2 Feb 2012

HAL is a multi-disciplinary open access archive for the deposit and dissemination of scientific research documents, whether they are published or not. The documents may come from teaching and research institutions in France or abroad, or from public or private research centers.
L'archive ouverte pluridisciplinaire HAL, est destinée au dépôt et à la diffusion de documents scientifiques de niveau recherche, publiés ou non, émanant des établissements d'enseignement et de recherche français ou étrangers, des laboratoires publics ou privés. 

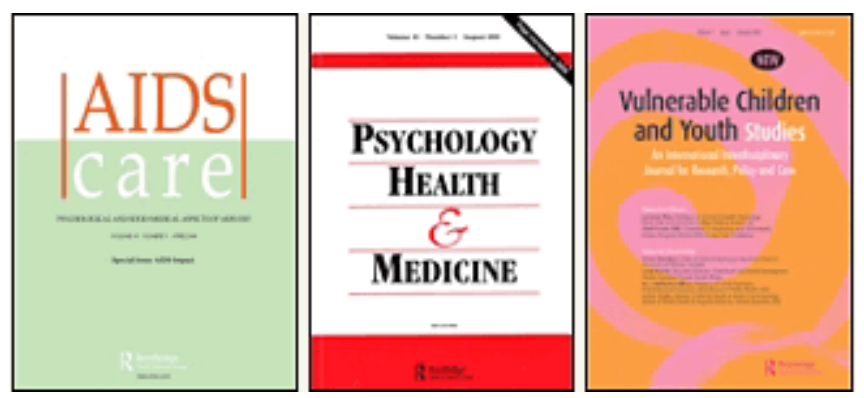

Knowledge of free voluntary HIV testing centres and willingness to do a test among migrants in Cayenne, French Guiana

\begin{tabular}{|r|l|}
\hline Journal: & $\begin{array}{l}\text { AIDS Care - Psychology, Health \& Medicine - Vulnerable Children } \\
\text { and Youth Studies }\end{array}$ \\
\hline Manuscript ID: & AC-2009-10-0555.R2 \\
\hline Journal Selection: & AIDS Care \\
\hline Keywords: & migrant, HIV testing, VCT, prevention, French Guiana \\
\hline \multicolumn{2}{|l}{} \\
\hline
\end{tabular}

SCHOLARONE ${ }^{m}$

Manuscripts 


\title{
Knowledge of free voluntary HIV testing centres and willingness to do a test among migrants in Cayenne, French Guiana
}

\begin{abstract}
In Cayenne, French Guiana, $80 \%$ of HIV+ patients followed at the hospital are migrants. Behavioral information is crucial for optimizing HIV testing for this vulnerable group. Predictors of ignorance of the existence of free VCT centre and willingness to get tested were investigated in 2006 among 398 migrants from Haiti, Guyana, Suriname, and Brazil using a structured questionnaire. Only $27 \%$ of migrants knew simultaneously about the existence of free VCT, its localisation and its operating hours. Factors associated with ignorance of the existence of free VCT centre were birthplace in Haiti, being in French Guiana for less than 3 years, not thinking one's birth country as strongly affected by HIV, and not thinking to be personally at risk for HIV. Factors independently associated with willingness to get tested were thinking to be at risk for HIV, birthplace in Brazil and Haiti, having a high integration level and fear of suffering if HIV test was positive. In order to improve testing among migrants, the accessibility of testing facilities and the knowledge of their whereabouts and operating hours must be improved to promote the desired behaviour among the majority of migrants which is often willing to do the test.
\end{abstract}

Keywords: migrant; French Guiana; HIV testing; VCT; prevention; risk perception. 


\section{INTRODUCTION}

Voluntary counselling and testing for HIV (VCT) is an important entry point to HIV prevention and care (Valdiserri, Holtgrave, \& West, 1999). The argument for promoting VCT services is that its uptake will foster HIV prevention, help to prevent mother-to-child transmission, and foster access to anti-retroviral therapy. Studies have shown that knowledge of one's HIV status is associated with positive behaviour change ("Efficacy of voluntary HIV-1 counselling and testing in individuals and couples in Kenya, Tanzania, and Trinidad: a randomised trial. The Voluntary HIV-1 Counseling and Testing Efficacy Study Group," 2000).

In France, since 1988, anonymous and free consultations (called CDAG) have been initiated to facilitate an individual and voluntary approach for HIV screening and counselling. These free VCT centres are also supposed to facilitate access to poor vulnerable populations. In Cayenne, French Guiana, there are 2 VCT centres. One is located at Cayenne general hospital and is opened three half day per week, the other is open weekday mornings. Rapid testing is not used and HIV test results are given in a few days.

French Guiana is the French overseas territory where the HIV epidemic is most preoccupying. The number of HIV+ patients is steadily increasing. In Cayenne, $80 \%$ of HIV + patients followed at the hospital are migrants coming from various countries among which Haiti, 53\%, Guyana 13\%, Brazil 7\%, and Suriname 3\% (Nacher et al., 2005; Nacher et al., 2007). In 2008, the HIV prevalence in pregnant women was $1.2 \%$ in the general population (Nacher et al., 2005). Specific prevalence by nationality in pregnant women is higher than $3 \%$ in several migrant communities (Nacher et al., 2005; Nacher et al., 2007). HIV positive migrant men are often 
diagnosed very late during the course of infection with half of HIV positive Haitian and Brazilian men being diagnosed with CD4 counts $<200$ per mm3 (Nacher et al., 2005). The standards of healthcare in French Guiana are close to those of metropolitan France. All HIV patients receive free antiretroviral treatments (including the most recent drugs) regardless of their origin or socio-economic level. Illegal migrants that are HIV+ obtain residence permits when no comparable treatment is available in their country. Migrants often arrive alone, from a high HIV prevalence country (Camara, 2006; CAREC/PAHO/WHO, 2007), and start a new emotional and sexual life. Economic dependence makes requiring systematic condom use with sexual partners difficult. Stigma and discrimination are still widespread and migrants' access to health information is often limited. All these parameters are potential drivers of the epidemic in migrant populations in French Guiana.

For decades, there have been repeated prevention and communication campaigns on HIV, and notably on the importance of HIV testing. However, no progress has been made on the proportion of diagnoses with CD4 counts $<200$ per mm3, notably among migrants. Similar challenges have also been observed elsewhere (Spielberg et al., 2003). There is thus a need to collect information in those groups to better respond to this diagnostic delay. Although, , UNAIDS recommends behavioural surveys in vulnerable groups every $2 / 3$ years in similar epidemiologic situations than that of French Guiana (Working Group on Global HIV/AIDS and STI Surveillance : Guidelines for Second Generation HIV Surveillance, 2000), this has never been done before.

Therefore, a study was conducted to collect evidence to improve testing. The objectives of the present study were: (1) to assess the level of knowledge about 
Cayenne VCT centres and their operating hours among migrants, (2) to describe willingness of migrants to get tested for HIV. 


\section{MATERIALS AND METHODS}

\section{Participants}

This study was part of the Agence Nationale de Recherche sur le SIDA et les Hépatites virales (ANRS) study on migrants conducted in 2007 to identify obstacles to HIV testing in high HIV risk migrant populations. The data collection period was from 2005 to 2007.

The study population was made of people coming from the four most at risk communities for HIV (Haiti, Brazil, Guyana, and Suriname) living in the area of Cayenne, French Guiana. The targeted sample size was of 400 persons, 100 in each studied communities and included $50 \%$ of males and $50 \%$ of females. The HIV status of persons was not known.

\section{Procedure}

The study relied on a structured and pre-coded anonymous KABP (Knowledge Attitudes Beliefs and Practices) questionnaire of 130 questions that assessed a range of demographic, psychosocial, behavioral, and economic factors. This questionnaire had common questions with a previous study in the general population in order to make comparisons (Halfen, 2008; Halfen, Fenies, Ung, \& Grémy, 2006). Street outreach recruitment strategy was used for this study. Respondents were recruited by interviewers from places were the studied migrant communities lived and congregated such as community neighbourhood or yellow fever vaccination centres. Interviewers asked the subjects from the targeted communities if they were willing to participate in the study. They were instructed to select a variety of persons and not to interrogate more than one person within a household. All participants were advised that the aim of the study was to determine social and sexual behaviours with special interest in 
HIV testing, that they could refuse to answer any questions and that participation was both voluntary and anonymous.

Those who agreed to participate were interviewed by a trained interviewer of the same nationality as the interviewed person at a time of their convenience. The interviewers were required to have a good knowledge of the questionnaire and to remain neutral whatever the responses were. Prior to the interview the respondents were asked to be sincere in their answers, and to sign the consent form. Responses were recorded on a paper questionnaire. Men were questioned by men and women by women. Persons were interrogated in a private place where no onlookers could influence their responses. Those who declined to participate were counted as nonresponders. The duration for completing the questionnaire was approximately 45 minutes per subject.

\section{Measures}

\section{Demographic Information}

Participants reported their age, gender, nationality, country of birth, marital status, number of children, language spoken and educational level.

\section{HIV risk behavior}

The following behaviors were surveyed for the past year: number of sex partners, concurrent sex partners, and nationality of partners. Others behavioral characteristics measured were tobacco/alcohol/drug consumption, history of condom use with the present partners, age at first sexual intercourse, age of the first partner at first sexual intercourse, and sex trade (for money, drugs, or other goods).

We also evaluated self evaluation of HIV knowledge, practical information sources to learn about HIV/AIDS, estimation of HIV risk in their own country and 
personal HIV risk, and knowledge of means of contamination using a standardized 9items composite subscale using specific targeted questions.

Immigration story, integration and social support

Self esteem was evaluated with an 8-item composite subscale, integration and perception of life in French Guiana were evaluated with time lived in French Guiana and a 9-item composite subscale.

\section{Economic level}

Participants reported their current employment status, housing conditions, possession of a residence permit / health insurance, and their principal mean of transportation. An 8-item composite subscale, based on material possession at migrant place, was created to evaluate global economic level.

\section{HIV testing}

Participants reported if they had ever had an HIV test, their opinion about the HIV test, fears linked to the HIV test, their practical and sociological barriers to do routinely HIV tests, their knowledge of existing free anonymous HIV testing place and their readiness and barriers to do an HIV test.

\section{Data analysis}

Composite subscales to measure the economic integration in French Guiana, self esteem, stress, risky behaviour and HIV knowledge levels of migrant persons were constructed using a methodology based on principal components analysis described elsewhere (Cortinovis, Vella, \& Ndiku, 1993; Vyas \& Kumaranayake, 2006).

Participant characteristics, knowledge of the existence, place and opening hours of VCT centres, and readiness to do a test were computed using simple 
proportions and means. Percentages in each community and gender were compared using Fisher's exact test.

A multivariate logistic regression was conducted to identify risk factors of ignorance of free HIV testing place and readiness to do an HIV test (Burnham \& D.R., 2002). Variables that were significant in bivariate analyses at $\mathrm{p}<0.10$ were included in the multivariate model. All statistical analyses were conducted using $\mathrm{R}$ 2.7.1. Statistical significance was set at $\mathrm{p}<0.05$. 


\section{RESULTS}

The participation rate was $80 \%$. The mean age of the population was 35 years ( $\mathrm{SD}=11$ years). A high proportion of the surveyed population was single or living apart (53\%). Only 62\% spoke fluent or a little French, the official language of French Guiana. Illiteracy (defined here as people who don't know or have limited knowledge of how to write and read) concerned $40 \%$ of the migrant population and $43 \%$ of them only received a primary education. Forty two percent were on welfare or unemployed. Twenty six percent didn't have health insurance and 51\% had no residence permit. Migrants had been living in French Guiana for a mean 10 years $(\mathrm{SD}=8)$. Sociodemographic variables and economic, integration, self esteem, stress, and risky behaviour composite subscales were detailed by birth country in the table 1 .

\section{Knowledge about VCT centres}

Twenty eight percent of migrants did not know that free HIV testing centres existed in Cayenne, with marked differences between communities: Haitian and Surinamese nationals seemed to be less aware (66\% and $62 \%$ respectively) than Brazilian and Guyanese nationals (75\% and $68 \%$ respectively). There was no significant difference between men and women (Table 2).

The location of a VCT centre was not known for $40 \%$ of migrants, with, there again, disparities between communities. In contrast with other nationalities, migrants from Guyana were significantly more aware of the whereabouts of a VCT centre $(86 \%)$.

The operating hours of VCT centres where unknown to $65 \%$ of the surveyed persons, with persons from Guyana being better informed than other nationalities. 
Only $58 \%$ of migrants knew simultaneously about the existence of a VCT centre and its localisation (Guyana: 82\%, Brazil: 47\%, Suriname: 57\%, Haiti: 46\%).

Furthermore, when adding operating hours, only 27\% (Guyana: 45\%, Brazil: 32\%, Suriname: 19\%, Haiti: $13 \%$ ) knew where and when to get free HIV testing.

There was a linear relation between level of knowledge about HIV and knowledge about VCT (linear trend chi2: p.value $<0.001$ ).

\section{Risk factors for ignorance of the existence of free VCT centre}

Risk factors associated with ignorance of the existence of a free VCT centre were: birthplace in Haiti, being in French Guiana for less than 3 years, not thinking one's birth country as strongly affected by HIV, and not thinking to be personally at risk for HIV (Table 3). Not knowing about the existence of a VCT centre was also found to be associated with having no education (p.value $<0.1$ ).

\section{Having ever done an HIV test}

Overall $61 \%$ of migrants ( $74 \%$ women and $46 \%$ of men) had done at least one HIV test. The breakdown per nationality showed that for Brazil, $75 \%$ of women but only $27.7 \%$ of men had ever done a test; for Suriname, $70 \%$ of women and $32 \%$ of men had ever done a test; for Haiti, $60 \%$ of women and $53 \%$ of men had ever done a test; and for Guyana, where $92 \%$ of women and $70 \%$ of men had ever done a test. Overall, $18 \%$ of those who had ever done a test had done it in their country of origin (Brazil 37\%, Guyana 17\%, Haiti 3\%, and Suriname 18\%), 4\% was not known, and 78\% had done the test in French Guiana.

\section{Willingness to do an HIV test}


Most migrants (76\%) were willing to do an HIV test after explanations about VCT centres (free of charge, anonymous, location and opening hours). There were differences between communities with Surinamese persons less likely to do the test (60\%), than the other nationalities (Brazil: 84\%, Guyana: 78\% and Haiti: 81\%). Persons having already done an HIV test were not more willing to do the test.

The three major explanations given by migrants for not wanting to do an HIV test were: having already done an HIV test (42\%), not wanting to know (10\%) and not having enough time to do the test (7\%). Thirty three percent answered other reason without specifying why.

Table 4 shows that, after adjusting for potential confounders, persons from Suriname and persons thinking to be at risk for HIV were more likely to be willing to do the test. However, the risk score calculated was not associated with increased willingness to do the test. Bivariate analysis showed that willingness to do the HIV test was associated with fear of suffering and fear of rejection if tested HIV positive, alcohol consumption, and a high integration score. Although the direction of the association remained in the multivariate analysis, the $\mathrm{p}$ value was no longer significant. Believing in HIV test confidentiality was not associated with an increased willingness to do the test (table 4).

\section{Actual fears experienced in past HIV tests}

The 3 main fears remembered by interviewed patients having previously had an HIV test were the fear of a positive result (73\%), the fear that the staff would repeat the result to other (39\%) and the fear of pain due to skin puncture (38\%). Haitians remembered HIV tests as particularly anxious moments. For Surinamese persons, the main fear was the fear linked to the possibility of a positive result, 
although all the other fears remained low (table 4). Men and women did not have significant differences in their reminiscence of fears during past HIV tests.

\section{DISCUSSION}

To intensify prevention, UNAIDS recommends to "know your epidemic and know your response" (Wilson \& Halperin, 2008). In this perspective, we have studied our most vulnerable population: migrants which, most likely, will represent 80 of our next 100 HIV diagnoses. Although, there are specific adaptations for treatment and care of migrants, efforts to adapt prevention and testing are lagging. When compared to metropolitan France, HIV testing is more widespread in French Guiana (Halfen, 2008; Halfen et al., 2006). Overall, $61.4 \%$ of men and $73.8 \%$ of women in the general population of French Guiana have done at least 1 HIV test in their life compared to $40.1 \%$ and $48.5 \%$ in metropolitan France, respectively. But this picture hides the fact that there are marked differences between populations. We here show that male migrants from Haiti, Suriname, and Brazil were less likely to have ever done an HIV test, which is consistent with what has previously been described in HIV patients (Nacher et al., 2005). On the contrary, men and women from Guyana seemed more likely to do the test and were particularly well informed about VCT centres. A difference between these nationalities is that most people from Guyana originate from the capital city Georgetown, whereas Haitians, Brazilians and Surinamese mostly come from rural areas, which are less likely to offer HIV prevention and testing. Finally, migrant women of the four communities were not less likely to have done a test than women from the general population of French Guiana. However, Haitian women were less likely than women from the general population to have ever done an HIV test. The greater use of testing in women is largely explained by mother and 
child clinics that propose testing to all pregnant women and some mothers consulting for their children's immunization. It has been shown that migrant men require innovative services (mobile services, rapid testing, home based testing...) that are compatible with their constraints and preferences (Otwombe, Ndindi, Ajema, \& Wanyungu, 2007).

Here, whereas most migrants were willing to get tested, in practice, a large proportion of them did not know where and when to get tested. This underlines the fact that, despite testing a large number of persons, our VCT testing facilities are not easily accessible for migrants: given the epidemiology of HIV in French Guiana this is a serious short coming (Cohen, Scribner, \& Farley, 2000; Mabunda, 2006). The finding underscores the importance of improving the availability of VCT, but also increasing public knowledge about the availability of such services. Solely improving information about the existing centres may not be sufficient for migrants (and non migrants) to memorize the precise days, hours, and places were they can get a free test, and therefore to significantly change testing behaviour. In addition, because of transportation issues and complicated lives, rapid testing would be an incentive to get tested for migrants. This however, is not, at the moment, a recommended testing method by French authorities.

Persons living in French Guiana for more than 3 years were more likely to know about the testing centres. This and the general willingness to do the test, suggests that information does percolate through the various communities. The perception of oneself and one's country to be at risk for HIV were independently associated with knowledge about VCT centres. The fact that, with time and integration, migrants do learn about the VCT centres and are willing to do the test 
suggests there is potential for improvement notably if facilities and information are adapted to the constraints of their lifestyles.

A number of variables were of borderline significance. Men were less likely to know about VCT centres but this trend was not statistically significant.

Unsurprisingly, the level of knowledge about HIV was linearly related to knowledge about VCT centres. Finally, although it was of borderline significance, the high risk subgroup of migrants having concurrent sexual partnerships seemed less likely to know about the VCT centres.

Being willing to do the HIV test is a prerequisite to actually doing the test. Turning HIV testing willingness into action requires the fulfilment of certain conditions. One of the conditions often reported is that people have to be convinced that VCT services are confidential (Fylkesnes, Haworth, Rosensvard, \& Kwapa, 1999). Data show here that despite of the anonymity provided by VCT centres, $52 \%$ of migrants did not think that HIV tests were confidential. Fear of confidentiality breach during a past HIV test was also very frequent. However, knowing that tests were confidential was not significantly associated with an increased willingness to do the test.

Unsurprisingly, thinking to be at risk for HIV was associated with increased willingness to do the test (Downing et al., 2001; Fylkesnes \& Siziya, 2004; Mbago, 2004). However, the actual risk score for HIV was not associated with an increased willingness to do the test. As the health belief model suggests, when people are conscious of their risk for HIV they will consider HIV testing a greater priority, thereby underscoring the need for increasing risk perception as a way of promoting VCT uptake. There is thus a need to educate migrants about HIV transmission, with 
an emphasis on transmission beyond high profile and high risk sexual acts (anal sex, sex work) that tend to overshadow the risk of transmission within serodiscordant couples.

The Haitian community, which represents half of all HIV patients in French Guiana, was markedly less informed about free VCT centres and were more likely to remember a past HIV tests as causing anxiety. A tentative explanation would be that the literacy rate of Haiti is much lower than that of other nationalities surveyed here (CIA, 2009). However, being able to read or write was not associated with knowledge of the VCT centres but the educational level was. Supernatural explanations of HIV/AIDS and intense stigma and discrimination in the Haitian community could explain both not knowing about HIV testing centres and high levels of fear.

A few limitations of this study should be mentioned. First, in the absence of an exhaustive list of migrants and given the magnitude of illegal immigration, random sampling was not possible. Therefore, the representativity of the selected migrants cannot be ascertained. Second, given the large number of variables, the relatively small sample size may have interfered with multivariate analysis. Third, although questionnaires are useful and often valid (James, Bignell, \& Gillies, 1991; McQueen, 1992; Upchurch et al., 1991), and although all persons were asked to agree to give sincere answers before the interview, the tendency to give socially desirable answers can affect the validity of answers on sexual behaviour.

In order to improve testing among migrants, knowledge of the health facilities and their confidentiality must be improved to promote the desired behaviour: getting tested. However, expecting persons with complicated lives to adopt new behaviours without adapting the VCT testing facilities to their difficulties is unrealistic. Getting 
migrant men to do the HIV test remains a challenge; proactive evidence-based strategies are required to incite them to get tested and reduce new infections, new AIDS cases and deaths for those ignoring their status.

ACKOWLEDGEMENTS: The study was funded by the Agence Nationale de la Recherche sur le SIDA et les Hépatites virales, ANRS. We would like to thank all participants and study staff. 


\section{REFERENCES}

Burnham, K. P., andD.R., A. (2002). Model Selection and Multimodel Inference: A Practical-Theoretic Approach (2nd ed.): Springer-Verlag.

Camara, B. (2006). 20 Years of the HIV/AIDS Epidemic in the Caribbean CAREC/PAHO/WHOo. Document Number)

CAREC/PAHO/WHO. (2007). The Caribbean HIV/AIDS Epidemic and the situation in member countries of the Caribbean Epidemiology Centre (CAREC) o. Document Number)

CIA. (2009). CIA World Factbook. from https://www.cia.gov/library/publications/the-world-factbook/index.html

Cohen, D. A., Scribner, R. A., andFarley, T. A. (2000). A structural model of health behavior: a pragmatic approach to explain and influence health behaviors at the population level. Prev Med, 30(2), 146-154.

Cortinovis, I., Vella, V., andNdiku, J. (1993). Construction of a socio-economic index to facilitate analysis of health data in developing countries. Soc Sci Med, 36(8), 1087-1097.

Downing, M., Knight, K., Reiss, T. H., Vernon, K., Mulia, N., Ferreboeuf, M., et al. (2001). Drug users talk about HIV testing: motivating and deterring factors. AIDS Care, 13(5), 561-577.

Efficacy of voluntary HIV-1 counselling and testing in individuals and couples in Kenya, Tanzania, and Trinidad: a randomised trial. The Voluntary HIV-1 Counseling and Testing Efficacy Study Group. (2000). Lancet, 356(9224), 103-112. 
Fylkesnes, K., Haworth, A., Rosensvard, C., andKwapa, P. M. (1999). HIV counselling and testing: overemphasizing high acceptance rates a threat to confidentiality and the right not to know. AIDS, 13(17), 2469-2474.

Fylkesnes, K., andSiziya, S. (2004). A randomized trial on acceptability of voluntary HIV counselling and testing. Trop Med Int Health, 9(5), 566-572.

Halfen, S. (2008). HIV screening in the French Antilles and Guiana adult general population in 2004, and comparison with the population living in mainland France. Bulletin épidémiologique hebdomadaire, 07-08, 55-58.

Halfen, S., Fenies, K., Ung, B., andGrémy, I. (2006). Les connaissances, attitudes, croyances et comportements face au VIH/SIDA aux Antilles et en Guyane: ORS Îles-de-Franceo. Document Number)

James, N. J., Bignell, C. J., andGillies, P. A. (1991). The reliability of self-reported sexual behaviour. AIDS, 5(3), 333-336.

Mabunda, G. (2006). Voluntary HIV counseling and testing: knowledge and practices in a rural South African village. J Transcult Nurs, 17(1), 23-29.

Mbago, M. C. (2004). Socio-demographic correlates of desire for HIV testing in Tanzania. Sex Health, 1(1), 13-21.

McQueen, D. (1992). Understanding sexual behaviour. AIDS, 6(3), 329-330.

Nacher, M., El Guedj, M., Vaz, T., Nasser, V., Randrianjohany, A., Alvarez, F., et al. (2005). Risk factors for late HIV diagnosis in French Guiana. AIDS, 19(7), 727-729.

Nacher, M., Huber, F., El Guedj, M., Vaz, T., Magnien, C., Djossou, F., et al. (2007). Risk factors for death among patients in French Guiana: 1996-2005. HIV Med, $8(7), 472-474$. 
Otwombe, K. N., Ndindi, P., Ajema, C., andWanyungu, J. (2007). Using VCT statistics from Kenya in understanding the association between gender and HIV. SAHARA J, 4(3), 707-710.

Spielberg, F., Branson, B. M., Goldbaum, G. M., Lockhart, D., Kurth, A., Celum, C. L., et al. (2003). Overcoming barriers to HIV testing: preferences for new strategies among clients of a needle exchange, a sexually transmitted disease clinic, and sex venues for men who have sex with men. J Acquir Immune Defic Syndr, 32(3), 318-327.

Upchurch, D. M., Weisman, C. S., Shepherd, M., Brookmeyer, R., Fox, R., Celentano, D. D., et al. (1991). Interpartner reliability of reporting of recent sexual behaviors. Am J Epidemiol, 134(10), 1159-1166.

Valdiserri, R. O., Holtgrave, D. R., andWest, G. R. (1999). Promoting early HIV diagnosis and entry into care. AIDS, 13(17), 2317-2330.

Vyas, S., andKumaranayake, L. (2006). Constructing socio-economic status indices: how to use principal components analysis. Health Policy Plan, 21(6), 459-468.

Wilson, D., andHalperin, D. T. (2008). "Know your epidemic, know your response": a useful approach, if we get it right. Lancet, 372(9637), 423-426.

Working Group on Global HIV/AIDS and STI Surveillance : Guidelines for Second Generation HIV Surveillance. (2000). Geneva: UNAIDS/WHOo. Document Number) 
Table 1: Socio-demographic characteristics of the study sample

\begin{tabular}{|c|c|c|c|c|c|}
\hline & Brazil (N=95) & Guyana $(\mathrm{N}=100)$ & Haiti ( $N=102)$ & Surinam $(\mathrm{N}=101)$ & Total $(\mathrm{N}=398)$ \\
\hline \multicolumn{6}{|l|}{ Sex } \\
\hline Female & $48(51 \%)$ & $50(50 \%)$ & $55(54 \%)$ & $60(59 \%)$ & $213(54 \%)$ \\
\hline Male & $47(49 \%)$ & $50(50 \%)$ & 47 (46\%) & $41(41 \%)$ & $185(46 \%)$ \\
\hline \multicolumn{6}{|l|}{ Age (Year) } \\
\hline$<25$ & $17(18 \%)$ & $15(15 \%)$ & $12(12 \%)$ & $27(27 \%)$ & $71(18 \%)$ \\
\hline $25-34$ & $32(34 \%)$ & $44(44 \%)$ & $36(35 \%)$ & 37 (36\%) & $149(37 \%)$ \\
\hline $35-45$ & $25(26 \%)$ & $25(25 \%)$ & $25(25 \%)$ & $27(27 \%)$ & $102(26 \%)$ \\
\hline$>45$ & $20(21 \%)$ & $16(16 \%)$ & $29(28 \%)$ & $9(9 \%)$ & $74(19 \%)$ \\
\hline No answer & $1(1 \%)$ & $0(0 \%)$ & $0(0 \%)$ & $1(1 \%)$ & $2(0 \%)$ \\
\hline \multicolumn{6}{|l|}{ French language spoken } \\
\hline No & $43(45 \%)$ & $30(30 \%)$ & $7(7 \%)$ & $47(47 \%)$ & 127 (32\%) \\
\hline Yes & $48(51 \%)$ & $70(70 \%)$ & 77 (75\%) & $52(51 \%)$ & $248(62 \%)$ \\
\hline No answer & $4(4 \%)$ & $0(0 \%)$ & $18(18 \%)$ & $2(2 \%)$ & $24(6 \%)$ \\
\hline \multicolumn{6}{|l|}{ Knowing how to read and write } \\
\hline No & $2(2 \%)$ & $5(5 \%)$ & $11(11 \%)$ & $17(17 \%)$ & $35(9 \%)$ \\
\hline Yes & $54(57 \%)$ & $75(75 \%)$ & $49(48 \%)$ & $51(50 \%)$ & $230(58 \%)$ \\
\hline A little & $36(38 \%)$ & $20(20 \%)$ & 39 (38\%) & $30(30 \%)$ & $125(31 \%)$ \\
\hline No answer & $3(3 \%)$ & $0 \%$ & $3(3 \%)$ & $3(3 \%)$ & $9(2 \%)$ \\
\hline \multicolumn{6}{|l|}{ Education } \\
\hline No education & $3(3 \%)$ & $2(2 \%)$ & $16(16 \%)$ & $22(22 \%)$ & $43(11 \%)$ \\
\hline Education & $77(81 \%)$ & $98(98 \%)$ & $85(83 \%)$ & $67(66 \%)$ & $328(82 \%)$ \\
\hline Others / Don't know / No answer & $15(16 \%)$ & $0 \%$ & $1(1 \%)$ & $12(12 \%)$ & $28(7 \%)$ \\
\hline Type of work & $a^{2}+2$ & & & & \\
\hline Regular job & $17(18 \%)$ & $16(16 \%)$ & $23(23 \%)$ & $16(16 \%)$ & $73(18 \%)$ \\
\hline Odds jobs & $38(40 \%)$ & $25(25 \%)$ & 27 (26\%) & $30(30 \%)$ & $120(30 \%)$ \\
\hline Welfare/no work & $17(18 \%)$ & $53(53 \%)$ & $45(44 \%)$ & $50(49 \%)$ & $165(42 \%)$ \\
\hline $\begin{array}{l}\text { Others / Don't know / No answer } \\
\text { Health insurance }\end{array}$ & $23(24 \%)$ & $6(6 \%)$ & $7(7 \%)$ & $5(5 \%)$ & $41(10 \%)$ \\
\hline No & $11(12 \%)$ & $53(53 \%)$ & $7(7 \%)$ & $31(31 \%)$ & $102(26 \%)$ \\
\hline Yes & $57(60 \%)$ & $46(46 \%)$ & $86(84 \%)$ & $69(68 \%)$ & $259(65 \%)$ \\
\hline Others / Don't know / No answer & $27(28 \%)$ & $1(1 \%)$ & $9(9 \%)$ & $1(1 \%)$ & $38(9 \%)$ \\
\hline \multicolumn{6}{|l|}{ Residence permit } \\
\hline No & $48(50 \%)$ & $65(65 \%)$ & $26(25 \%)$ & $65(64 \%)$ & $204(51 \%)$ \\
\hline Yes & $36(38 \%)$ & $33(33 \%)$ & $60(59 \%)$ & $33(33 \%)$ & $163(41 \%)$ \\
\hline Others / Don't know / No answer & $11(12 \%)$ & $2(2 \%)$ & $16(16 \%)$ & $3(3 \%)$ & $32(8 \%)$ \\
\hline \multicolumn{6}{|l|}{ Marital status } \\
\hline Married living with partner & $14(15 \%)$ & $10(10 \%)$ & $35(34 \%)$ & $6(6 \%)$ & $65(16 \%)$ \\
\hline Not married but Living with partner & $25(26 \%)$ & $22(22 \%)$ & $20(20 \%)$ & $46(45 \%)$ & $114(29 \%)$ \\
\hline Single or living apart & $55(58 \%)$ & $68(68 \%)$ & $47(46 \%)$ & $43(43 \%)$ & $213(53 \%)$ \\
\hline No answer & $1(1 \%)$ & $0(0 \%)$ & $0(0 \%)$ & $6(6 \%)$ & $7(2 \%)$ \\
\hline \multicolumn{6}{|l|}{ Time in French Guiana } \\
\hline$<3$ years & $25(26 \%)$ & $23(23 \%)$ & $7(7 \%)$ & $10(10 \%)$ & $65(16 \%)$ \\
\hline $3-10$ years & $36(38 \%)$ & $50(50 \%)$ & 47 (46\%) & $48(47 \%)$ & $181(46 \%)$ \\
\hline$>10$ years & $31(33 \%)$ & 27 (27\%) & 45 (44\%) & $42(42 \%)$ & $145(36 \%)$ \\
\hline No answer & $3(3 \%)$ & $0(0 \%)$ & $3(3 \%)$ & $1(1 \%)$ & $8(2 \%)$ \\
\hline \multicolumn{6}{|l|}{ Integration level \$ } \\
\hline Low & $50(53 \%)$ & $24(24 \%)$ & $34(33 \%)$ & $51(50 \%)$ & $160(40 \%)$ \\
\hline Middle & $24(25 \%)$ & $56(56 \%)$ & $39(38 \%)$ & $41(41 \%)$ & $160(40 \%)$ \\
\hline High & $21(22 \%)$ & $20(20 \%)$ & $29(29 \%)$ & $9(9 \%)$ & $79(20 \%)$ \\
\hline \multicolumn{6}{|l|}{ Self esteem level \$ } \\
\hline Low & $39(41 \%)$ & $31(31 \%)$ & $52(51 \%)$ & $38(37 \%)$ & $160(40 \%)$ \\
\hline Middle & $34(36 \%)$ & $50(50 \%)$ & $42(41 \%)$ & $33(33 \%)$ & $160(40 \%)$ \\
\hline High & $22(23 \%)$ & $19(19 \%)$ & $8(8 \%)$ & $30(30 \%)$ & $79(20 \%)$ \\
\hline \multicolumn{6}{|l|}{ Stress level \$ } \\
\hline Low & $35(37 \%)$ & $48(48 \%)$ & $22(22 \%)$ & $54(53 \%)$ & $160(40 \%)$ \\
\hline Middle & $41(43 \%)$ & $35(35 \%)$ & $50(49 \%)$ & $34(34 \%)$ & $160(40 \%)$ \\
\hline High & $19(20 \%)$ & $17(17 \%)$ & $30(29 \%)$ & $13(13 \%)$ & $79(20 \%)$ \\
\hline \multicolumn{6}{|l|}{ Economic level \$ } \\
\hline Low & 27 (28\%) & $52(52 \%)$ & $26(26 \%)$ & $55(54 \%)$ & $160(40 \%)$ \\
\hline Middle & $38(40 \%)$ & 35 (35\%) & 47 (46\%) & 39 (39\%) & $160(40 \%)$ \\
\hline High & $30(32 \%)$ & $13(13 \%)$ & $29(28 \%)$ & $7(7 \%)$ & $79(20 \%)$ \\
\hline \multicolumn{6}{|l|}{ Risk behavior level \$ } \\
\hline Low & $41(43 \%)$ & $11(11 \%)$ & 55 (54\%) & $53(52 \%)$ & $160(40 \%)$ \\
\hline Middle & $35(37 \%)$ & $51(51 \%)$ & 35 (34\%) & $39(39 \%)$ & $160(40 \%)$ \\
\hline High & $19(20 \%)$ & $38(38 \%)$ & $12(12 \%)$ & $9(9 \%)$ & $79(20 \%)$ \\
\hline
\end{tabular}

\$: Composite subscales constructed using a methodology based on principal components analysis (see methodology). 
Table 2: Knowledge of migrants on VCT Centre by sex and birth country.

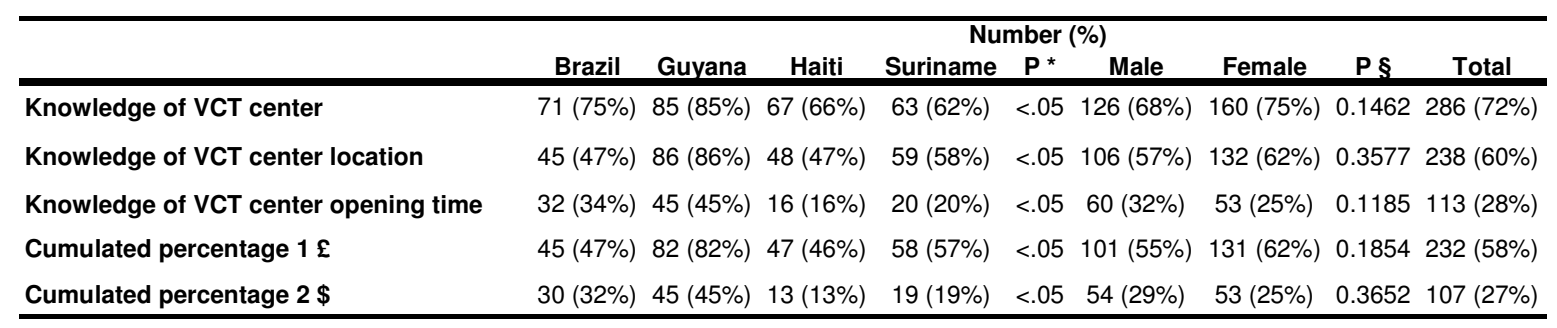

*: Fisher's exact test.

§: Fisher's exact test.

$\mathfrak{f}$ : Cumulated 1 represents counts and proportions of persons who knew simultaneously the existence of a free VCT centre and its location.

\$: Cumulated 2 represents counts and proportions of persons who knew simultaneously the existence of a free VCT centre, its location and opening time. 
Table 3: Multivariate logistic regression predicting knowledge of the Cayenne VCT centres among 399 migrants in Cayenne, French Guiana. (£)

\begin{tabular}{|c|c|c|c|c|}
\hline & Nr Knowing/Total (\%) \# & Crude odds Ratios( 95.Cl) & Adj. odds Ratios( 95.Cl) & $\overline{\mathbf{P}}$ \\
\hline \multicolumn{5}{|l|}{ Birth country } \\
\hline Brazil & $71 / 95(75)$ & 1 & 1 & - \\
\hline Guyana & $85 / 100(85)$ & $1.42(0.63-3.18)$ & $1.29(0.33-5.06)$ & 0.713 \\
\hline Haiti & $67 / 102(66)$ & $0.5(0.25-1.03)$ & $0.2(0.06-0.66)$ & $0.008^{\star}$ \\
\hline Suriname & 63/101 (62) & $0.71(0.33-1.5)$ & $0.79(0.25-2.51)$ & 0.691 \\
\hline \multicolumn{5}{|l|}{ Knowing how to read and write } \\
\hline No & $17 / 35(49)$ & 1 & 1 & - \\
\hline Yes & $186 / 230(81)$ & $4.1(1.73-9.69)$ & $1.08(0.21-5.45)$ & 0.924 \\
\hline A little & $78 / 125(62)$ & $1.77(0.74-4.24)$ & $0.84(0.19-3.71)$ & 0.814 \\
\hline \multicolumn{5}{|l|}{ Education } \\
\hline No education & $20 / 43(47)$ & 1 & 1 & - \\
\hline Education & $248 / 328(76)$ & $3.69(1.7-8.01)$ & $4.05(0.98-16.76)$ & $0.054 \S$ \\
\hline $\begin{array}{l}\text { Others / Don't know / No answer } \\
\text { Health insurance }\end{array}$ & $19 / 28(68)$ & $2.43(0.78-7.55)$ & $1.42(0.25-8.08)$ & 0.692 \\
\hline No & 60/102 (59) & 1 & 1 & - \\
\hline Yes & $201 / 259(78)$ & $2.78(1.57-4.92)$ & $2.79(1.04-7.48)$ & $0.042^{\star}$ \\
\hline Others / Don't know / No answer & $26 / 38(68)$ & $1.75(0.66-4.66)$ & $2.11(0.49-9.02)$ & 0.315 \\
\hline \multicolumn{5}{|l|}{ Residence permit } \\
\hline No & $137 / 204(67)$ & 1 & 1 & - \\
\hline Yes & $129 / 163(79)$ & $2.32(1.29-4.16)$ & $1.32(0.51-3.43)$ & 0.573 \\
\hline Others / Don't know / No answer & $21 / 32(66)$ & $1.05(0.43-2.56)$ & $0.8(0.22-2.89)$ & 0.734 \\
\hline \multicolumn{5}{|l|}{ Time in French Guiana } \\
\hline$<3$ years & $32 / 65(49)$ & 1 & 1 & - \\
\hline $3-10$ years & $139 / 181(77)$ & $4.92(2.46-9.81)$ & $7.4(2.84-19.28)$ & $<0.001^{\star}$ \\
\hline$>10$ years & $111 / 145(77)$ & $4.55(2.23-9.3)$ & $6.07(2.04-18.08)$ & $0.001^{*}$ \\
\hline \multicolumn{5}{|l|}{ Integration level \$ } \\
\hline Low & $105 / 160(66)$ & 1 & 1 & - \\
\hline Middle & $113 / 160(71)$ & $1.47(0.84-2.58)$ & $1.02(0.48-2.19)$ & 0.952 \\
\hline High & $69 / 79(87)$ & $3.13(1.41-6.96)$ & $1.77(0.63-4.98)$ & 0.281 \\
\hline \multicolumn{5}{|l|}{ HIV knowledge level \$ } \\
\hline Low & $41 / 79(52)$ & 1 & 1 & - \\
\hline Middle & $114 / 160(71)$ & $1.87(0.96-3.63)$ & $1.97(0.83-4.66)$ & 0.125 \\
\hline High & $132 / 160(83)$ & $3.26(1.62-6.54)$ & $1.99(0.75-5.29)$ & 0.166 \\
\hline \multicolumn{5}{|l|}{ Self evaluation of HIV knowledge } \\
\hline Bad & $84 / 130(65)$ & 1 & 1 & - \\
\hline Good & $196 / 257(76)$ & $1.5(0.88-2.57)$ & $0.85(0.38-1.89)$ & 0.689 \\
\hline \multicolumn{5}{|l|}{ Thinking to be at risk fot HIV } \\
\hline No & $185 / 266(70)$ & 1 & 1 & - \\
\hline Yes & $98 / 116(84)$ & $2.01(1.08-3.77)$ & $2.55(1.12-5.79)$ & $0.026^{\star}$ \\
\hline \multicolumn{5}{|l|}{$\begin{array}{l}\text { Thinking birth country is at high } \\
\text { risk for HIV }\end{array}$} \\
\hline No & $53 / 93(57)$ & 1 & 1 & - \\
\hline Yes & 223/285 (78) & $3.17(1.82-5.52)$ & $4.18(1.95-8.94)$ & $<0.001^{*}$ \\
\hline \multicolumn{5}{|l|}{ Fear of HIV } \\
\hline Not important & $66 / 105(63)$ & $1 \longdiv { V }$ & 1 & - \\
\hline Important & $214 / 282(76)$ & $1.79(1.02-3.15)$ & $1.57(0.7-3.48)$ & 0.271 \\
\hline \multicolumn{5}{|l|}{ Knowing an HIV + person } \\
\hline No & $160 / 225(71)$ & 1 & 1 & - \\
\hline Yes & $93 / 115(81)$ & $1.88(0.98-3.58)$ & $0.96(0.39-2.38)$ & 0.937 \\
\hline Others / Don't know / No answer & $34 / 59(58)$ & $0.56(0.28-1.12)$ & $0.44(0.16-1.2)$ & 0.11 \\
\hline \multicolumn{5}{|l|}{ Risk behavior level \$ } \\
\hline Low & $106 / 160(66)$ & 1 & 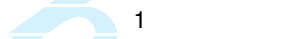 & - \\
\hline Middle & $124 / 160(78)$ & $1.84(1.02-3.31)$ & $1.52(0.69-3.37)$ & 0.298 \\
\hline High & $57 / 79(72)$ & $1.1(0.55-2.21)$ & $1.6(0.55-4.67)$ & 0.387 \\
\hline \multicolumn{5}{|l|}{ Having ever used a condom } \\
\hline No & $61 / 98(62)$ & 1 & 1 & - \\
\hline Yes & $207 / 269(77)$ & $1.59(0.91-2.78)$ & $1.21(0.57-2.58)$ & 0.625 \\
\hline
\end{tabular}

$£$ : Analysis of knowledge of free VCT centres from a multivariate logistic regression model. Only variables with a p.value $<.1$ in bivariate logistic regression are presented in the table and were incorporated in the final multivariate analysis.

*: P.value $<.05$

$\S:$ P.value $<.1$

$\$$ : Composite subscales constructed using a methodology based on principal components analysis (see methodology).

\#: Number of people knowing the existence of the Cayenne VCT centres for each variables category. i.e.: of the 35 surveyed migrants who did not know how to read and write, 17 (49\%) were aware of the existence of the VCT centres in Cayenne. 
Table 4: Multivariate logistic regression predicting willingness to do an HIV test among 399 migrants in Cayenne, French Guiana. (£)

\begin{tabular}{|c|c|c|c|c|}
\hline & Nr willing/Total (\%) \# & Crude odds Ratios( 95.CI) & Adj.odds Ratios (95.Cl) & $\overline{\mathbf{P}}$ \\
\hline \multicolumn{5}{|l|}{ Birth country } \\
\hline Brazil & 80/95 (84) & 1 & 1 & - \\
\hline Guyana & $78 / 100(78)$ & $0.49(0.19,1.27)$ & $0.31(0.1,1.02)$ & $0.054 \S$ \\
\hline Haiti & $83 / 102(81)$ & $0.74(0.27,2.03)$ & $0.7(0.22,2.22)$ & 0.54 \\
\hline Suriname & $61 / 101(60)$ & $0.17(0.07,0.44)$ & $0.24(0.08,0.71)$ & $0.01^{*}$ \\
\hline \multicolumn{5}{|c|}{ Thinking to be at risk fot HIV } \\
\hline No & $193 / 266(73)$ & 1 & 1 & - \\
\hline Yes & $102 / 116(88)$ & $3.65(1.65,8.05)$ & $2.42(1.02,5.75)$ & $0.045^{\star}$ \\
\hline \multicolumn{5}{|l|}{ Integration level \$ } \\
\hline Low & $109 / 160(68)$ & 1 & 1 & - \\
\hline Middle & $124 / 160(78)$ & $1.37(0.74,2.55)$ & $1.4(0.68,2.88)$ & 0.365 \\
\hline High & $69 / 79(87)$ & $2.85(1.21,6.7)$ & $2.33(0.87,6.23)$ & $0.092 \S$ \\
\hline \multicolumn{5}{|c|}{ Sex first intercourse age } \\
\hline$<15$ & $90 / 113(80)$ & 1 & 1 & - \\
\hline $15-17$ & $120 / 170(71)$ & $0.68(0.35,1.3)$ & $0.74(0.35,1.55)$ & 0.423 \\
\hline$>17$ & $65 / 79(82)$ & $1.37(0.57,3.31)$ & $1.08(0.38,3.1)$ & 0.888 \\
\hline \multicolumn{5}{|l|}{ Risk behavior level \$ } \\
\hline Low & $130 / 160(81)$ & 1 & 1 & - \\
\hline Middle & $112 / 160(70)$ & $0.55(0.29,1.05)$ & $0.58(0.27,1.29)$ & 0.182 \\
\hline High & $60 / 79(76)$ & $0.85(0.38,1.94)$ & $0.65(0.24,1.79)$ & 0.406 \\
\hline \multicolumn{5}{|c|}{ Believing in HIV test confidentiality } \\
\hline No & $151 / 210(72)$ & 1 & 1 & - \\
\hline Yes & $144 / 176(82)$ & $1.65(0.92,2.96)$ & $1.05(0.5,2.22)$ & 0.899 \\
\hline \multicolumn{5}{|c|}{$\begin{array}{l}\text { High fear to be rejected if test is } \\
\text { positive }\end{array}$} \\
\hline No & $131 / 189(69)$ & 1 & 1 & - \\
\hline Yes & $156 / 184(85)$ & $2.44(1.35,4.43)$ & $1.65(0.8,3.41)$ & 0.179 \\
\hline \multicolumn{5}{|c|}{$\begin{array}{l}\text { High fear of suffering if test is } \\
\text { positive }\end{array}$} \\
\hline No & $84 / 122(69)$ & 1 & 1 & - \\
\hline Yes & $210 / 258(81)$ & $2.03(1.13,3.65)$ & $1.94(0.91,4.13)$ & $0.086 \S$ \\
\hline \multicolumn{5}{|c|}{ Time to the nearest doctor } \\
\hline$<15 \min$ & $101 / 132(77)$ & 1 & 1 & - \\
\hline 15-30min & $132 / 167(79)$ & $0.5(0.24,1.06)$ & $0.84(0.32,2.24)$ & 0.733 \\
\hline$>30 \mathrm{~min}$ & $45 / 71(63)$ & $1.16(0.59,2.25)$ & $1.53(0.71,3.29)$ & 0.28 \\
\hline \multicolumn{5}{|l|}{ Alcohool consumption } \\
\hline rarely/never & $200 / 275$ (73) & 1 & 1 & - \\
\hline sometimes/often & $100 / 120(83)$ & $2(1,3.99)$ & $1.92(0.85,4.32)$ & 0.114 \\
\hline \multicolumn{5}{|c|}{$\begin{array}{l}\text { Hypothetical reaction towards partner } \\
\text { after learning partner's HIV infection }\end{array}$} \\
\hline Leave him/her & $34 / 39$ (87) & 1 & 1 & - \\
\hline Help him/her & $153 / 192(80)$ & $0.62(0.17,2.2)$ & $0.73(0.17,3.12)$ & 0.671 \\
\hline Don't know / No answer & $115 / 168(68)$ & $0.4(0.11,1.46)$ & $1.25(0.29,5.43)$ & 0.768 \\
\hline
\end{tabular}

$\mathfrak{f}$ : Analysis of readiness to do an HIV test from a multivariate logistic regression model. With the exception of having had a previous HIV test, only variables with a p.value inferior to 0.1 in bivariate analysis are presented in the table and were incorporated in the final multivariate analysis.

*: P.value $<.05$

$\S:$ P.value $<.1$

\$: Composite subscales constructed using a methodology based on principal components analysis (see methodology).

\#: Number of people who were willing to do an HIV test for each variables category. i.e. : of the 266 surveyed migrants who did not think to be at risk for HIV, 193 (73\%) were aware of the existence of theVCT centres in Cayenne. 
Table 5: Fears during a past HIV test among migrants by sex and birth country.

\begin{tabular}{lcccccccccc}
\hline & Brazil & Guyana & Haiti & Suriname & $\boldsymbol{P} *^{*}$ & Female & Male & $\boldsymbol{P} \xi$ & Total \\
\hline Fear of result & $35(73)$ & $53(65)$ & $33(66)$ & $49(92)$ & $<.05$ & $111(74)$ & $59(73)$ & 1 & $170(73)$ \\
$\begin{array}{l}\text { Fear to meet someone } \\
\text { known }\end{array}$ & $10(23)$ & $16(20)$ & $35(74)$ & $7(13)$ & $<.05$ & $40(27)$ & $28(37)$ & 0.1683 & $68(31)$ \\
$\begin{array}{l}\text { Fear of pain due to skin } \\
\text { puncture }\end{array}$ & $11(26)$ & $18(23)$ & $38(78)$ & $18(34)$ & $<.05$ & $53(36)$ & $32(42)$ & 0.3868 & $85(38)$ \\
$\begin{array}{l}\text { Fear of people staring in } \\
\text { the waiting room }\end{array}$ & $10(23)$ & $15(19)$ & $36(75)$ & $8(15)$ & $<.05$ & $44(30)$ & $25(33)$ & 0.6487 & $69(31)$ \\
$\begin{array}{l}\text { Fear of the critical } \\
\text { judgement of the doctor }\end{array}$ & $12(28)$ & $21(27)$ & $39(81)$ & $2(4)$ & $<.05$ & $47(32)$ & $27(36)$ & 0.6551 & $74(33)$ \\
$\begin{array}{l}\text { Fear that the staff repeats } \\
\text { results to other }\end{array}$ & $14(32)$ & $34(44)$ & $31(72)$ & $5(9)$ & $<.05$ & $53(37)$ & $31(42)$ & 0.462 & $84(39)$ \\
\hline
\end{tabular}

*: Fisher's exact test

$\S:$ Fisher's exact test 